\title{
Optically decomposed near-band-edge structure and excitonic transitions in
} $\mathrm{Ga}_{2} \mathrm{~S}_{3}$

Received

20 May 2014

Accepted

28 July 2014

Published

21 August 2014

\section{Correspondence and} requests for materials should be addressed to

C.-H. (chho@mail. ntust.edu.tw)
Ching-Hwa Ho ${ }^{1,2}$ \& Hsin-Hung Chen'

'Graduate Institute of Applied Science and Technology, National Taiwan University of Science and Technology, Taipei 106, Taiwan, ${ }^{2}$ Graduate Institute of Electro-Optical Engineering and Department of Electronic and Computer Engineering, National Taiwan University of Science and Technology, Taipei 106, Taiwan.

The band-edge structure and band gap are key parameters for a functional chalcogenide semiconductor to its applications in optoelectronics, nanoelectronics, and photonics devices. Here, we firstly demonstrate the complete study of experimental band-edge structure and excitonic transitions of monoclinic digallium trisulfide $\left(\mathrm{Ga}_{2} \mathrm{~S}_{3}\right)$ using photoluminescence $(\mathrm{PL})$, thermoreflectance (TR), and optical absorption measurements at low and room temperatures. According to the experimental results of optical measurements, three band-edge transitions of $\mathrm{E}_{\mathrm{A}}=3.052 \mathrm{eV}, \mathrm{E}_{\mathrm{B}}=3.240 \mathrm{eV}$, and $\mathrm{E}_{\mathrm{C}}=3.328 \mathrm{eV}$ are respectively determined and they are proven to construct the main band-edge structure of $\mathrm{Ga}_{2} \mathrm{~S}_{3}$. Distinctly optical-anisotropic behaviors by orientation- and polarization-dependent TR measurements are, respectively, relevant to distinguish the origins of the $\mathrm{E}_{\mathrm{A}}, \mathrm{E}_{\mathrm{B}}$, and $\mathrm{E}_{\mathrm{C}}$ transitions. The results indicated that the three band-edge transitions are coming from different origins. Low-temperature PL results show defect emissions, bound-exciton and free-exciton luminescences in the radiation spectra of $\mathrm{Ga}_{2} \mathrm{~S}_{3}$. The below-band-edge transitions are respectively characterized. On the basis of experimental analyses, the optical property of near-band-edge structure and excitonic transitions in the monoclinic $\mathrm{Ga}_{2} \mathrm{~S}_{3}$ crystal is revealed.

$\mathrm{a}_{2} \mathrm{~S}_{3}$ is an important member of III-VI compounds (i.e. III: In, Ga, and VI: S, Se, Te), which may possess the widest band gap. Dissimilar to the other III-V compounds (e.g. GaAs and InP) having the strongest covalent bond, the misvalency between the III and VI atoms usually renders a III-VI compound possessing different stoichiometries, diversified crystal phases, and various lattice forms ${ }^{1-3}$. For the gallium chalcogenides, $\mathrm{GaS}$ and $\mathrm{Ga}_{2} \mathrm{~S}_{3}$ are the general constituents existed in the gallium sulfides ${ }^{4,5}$ while the $\mathrm{GaSe}$ and $\mathrm{Ga}_{2} \mathrm{Se}_{3}$ are the common stoichiometric elements formed in the gallium selenides ${ }^{6,7}$. The GaSe and GaS compounds may crystallize in the hexagonal layered structure but possess different stacking formula (i.e. GaSe is in $\varepsilon$ stacking phase and $\mathrm{GaS}$ in $\beta$ polytype $)^{8}$. The stacking deviation in $\mathrm{GaX}(\mathrm{X}=\mathrm{S}, \mathrm{Se})$ will make GaSe a direct semiconductor with an energy gap close to $2 \mathrm{eV}$ whereas the $\mathrm{GaS}$ material becomes an indirect semiconductor with an indirect gap of $\sim 2.53 \mathrm{eV}^{4}$. $\mathrm{Ga}_{2} \mathrm{Se}_{3}$ may possess a defective zinc-blende structure in which one-third part of cation sites are vacant randomly in the lattice ${ }^{7}$. It is naturally a defect semiconductor with a direct band gap around $2-2.4 \mathrm{eV}^{9,10}$. All the gallium chalcogenides $\mathrm{GaSe}, \mathrm{GaS}$, and $\mathrm{Ga}_{2} \mathrm{Se}_{3}$ have the values of band gaps below $2.55 \mathrm{eV}$, which can only be catalogued into the visible-range materials, not for the blue to UV applications. $\mathrm{Ga}_{2} \mathrm{~S}_{3}$ is also a defect semiconductor with various existing phases of monoclinic ${ }^{5,11,12}$, hexagonal ${ }^{3}$, and cubic $^{13,14}$ owing to the misvalency of the III-Ga and VI-S elements. The most stable and generally found crystal structure of $\mathrm{Ga}_{2} \mathrm{~S}_{3}$ is the monoclinic phase. Previous studies claimed that the doped $\left(\mathrm{Cr}\right.$ and $\mathrm{Fe}$ ) and undoped $\mathrm{Ga}_{2} \mathrm{~S}_{3}$ can be a luminescent material with emitting wavelengths ranging from near infrared to blue portion ${ }^{15,16}$. A gold-doped chalcogenide glass containing the $\mathrm{Ga}_{2} \mathrm{~S}_{3}$ nanocrystals can be applied in the third-order nonlinear optics ${ }^{17}$. $\mathrm{Ga}_{2} \mathrm{~S}_{3}$ is a wide-bandgap semiconductor, however, to date, discrepant values of band gaps ranging from 2.5 to $3.4 \mathrm{eV}$ have ever been found in the literatures ${ }^{18,19}$. This result is owing to the uncertainty on the crystal quality and the lack of knowledge to the optically decomposed experimental band-edge structure of $\mathrm{Ga}_{2} \mathrm{~S}_{3}$.

In this paper, we demonstrate the detailed characterization of near-band-edge structure (below and above band gap) of high-quality $\mathrm{Ga}_{2} \mathrm{~S}_{3}$ crystals using optical techniques of polarized thermoreflectance (PTR), photoluminescence (PL), and optical-absorption measurements in the temperature range between 15 and $300 \mathrm{~K}$. Single crystals of $\mathrm{Ga}_{2} \mathrm{~S}_{3}$ were grown by chemical vapor transport (CVT) method using $\mathrm{ICl}_{3}$ as the transport agent. The 
as-grown crystals are essentially transparent and light-yellow colored. High-resolution transmission electron microscopy (HRTEM), X-ray diffraction (XRD), and Raman measurements confirmed monoclinic phase of the as-grown $\mathrm{Ga}_{2} \mathrm{~S}_{3}$ crystals. The lattice parameters and crystal structure are determined. The below-band-edge emissions of $\mathrm{Ga}_{2} \mathrm{~S}_{3}$ including defects, bound-exciton (BX), and freeexciton (FX) luminescences are respectively probed by PL and temperature-dependent PL measurements. The low-temperature TR spectra clearly show four band-edge transitions denoted as $E_{A}, E_{B}$, $\mathrm{E}_{\mathrm{C} 1}$, and $\mathrm{E}_{\mathrm{C} 2}$ detected in the vicinity of the band gap. The $\mathrm{E}_{\mathrm{A}}$ transition is the direct band gap of $\mathrm{Ga}_{2} \mathrm{~S}_{3}$ which is determined to be $\sim 3.052 \mathrm{eV}$ at room temperature. The $\mathrm{E}_{\mathrm{B}}, \mathrm{E}_{\mathrm{C} 1}$, and $\mathrm{E}_{\mathrm{C} 2}$ transitions are the band-edge excitons and they respectively demonstrate orientation and polarization dependences of anisotropic characters with respect to the $c$ plane of $\mathrm{Ga}_{2} \mathrm{~S}_{3}$. The $\mathrm{E}_{\mathrm{B}}$ exciton behaves like a free-exciton emission (PL) from the $c$-plane $\mathrm{Ga}_{2} \mathrm{~S}_{3}$ while the $\mathrm{E}_{\mathrm{C} 1}$ and $\mathrm{E}_{\mathrm{C} 2}$ transitions belong to an excitonic series with an effective Rydberg constant (i.e. binding energy) of about $R_{y d} \approx 68 \mathrm{meV}$. Photovoltage-current (Photo V-I) measurements of the $\mathrm{Ga}_{2} \mathrm{~S}_{3}$ sample under different illumination conditions of dark, halgen lamp, and 405-nm laser are, respectively, carried out to evaluate the photoelectric-conversion behavior of the $\mathrm{Ga}_{2} \mathrm{~S}_{3}$ crystal. On the basis of the experimental analyses of PL, TR, PTR, and Photo V-I measurements, the near-band-edge transitions and excitonic structures of the monoclinic $\mathrm{Ga}_{2} \mathrm{~S}_{3}$ are characterized. The direct-gap chalcogenide can be a functional material suitable for white-light emitting device and UV solar-energy conversion cell.

\section{Results}

Crystallinity and crystal structure. Displayed on the left side of Fig. 1(a) is the HRTEM image of the as-grown $\mathrm{Ga}_{2} \mathrm{~S}_{3}$ crystal on the $c$ plane. Regular and clear atomic sites for the periodically-arranged lattice of the $c$-plane $\mathrm{Ga}_{2} \mathrm{~S}_{3}$ can be observed in HRTEM image, indicating that excellent crystallinity of the $\mathrm{Ga}_{2} \mathrm{~S}_{3}$ can be obtained by the CVT growth with $\mathrm{ICl}_{3}$ as the transport agent. The better crystal quality of $\mathrm{Ga}_{2} \mathrm{~S}_{3}$ can also be evident in the upper-right side of Fig. 1(a) by a fast Fourier transformation (FFT) image of the HRTEM picture for revealing distinct and clear dot pattern (i.e. no rings formation). The selected-area electron diffraction (SAED) pattern of the $\mathrm{Ga}_{2} \mathrm{~S}_{3}$ with the zone axis along [001] is also shown in the right side of Fig. 1(a). The apparent and obvious dot spots of the SAED pattern of $\mathrm{Ga}_{2} \mathrm{~S}_{3}$ verifies high crystalline quality of the crystal. The dot spots also represent several sets of complete crystalline planes of $\mathrm{Ga}_{2} \mathrm{~S}_{3}$, e.g. the (200) spot as indicated in the SAED pattern of Fig. 1(a). As shown in the HRTEM image in Fig. 1(a), the atomic arrangements of the $c$-plane $\mathrm{Ga}_{2} \mathrm{~S}_{3}$ can allow us to distinguish the $a$ and $b$ axes of the crystal plane. Depicted by the green-arrow lines in the HRTEM image are the indications of the $a$ and $b$ axes on the $c$-plane $\mathrm{Ga}_{2} \mathrm{~S}_{3}$. The angle lying in between the $a$ and $b$ axes is $\gamma\left(\approx 140^{\circ}\right)$. From the HRTEM image of Fig. 1(a), the estimate of inter-planar spacing of $d_{(200)}$ is about $0.55 \mathrm{~nm}$ (i.e. $a=1.1 \mathrm{~nm}$ ) while the lattice spacing of the $b$ axis can be determined to be $d_{(010)}=$ $2 d_{(020)} \approx 2 \times\left[0.31 \mathrm{~nm} / \cos \left(50^{\circ}\right)\right]=0.96 \mathrm{~nm}$. The crystal symmetry of the $\mathrm{Ga}_{2} \mathrm{~S}_{3}$ crystal observed by the HRTEM image of the $c$ plane in Fig. 1(a) seems to be a monoclinic phase. It can also be verified by the XRD measurement [see supplementary information (SI)]. The lattice constants from the XRD result are determined to be $a=1.111 \mathrm{~nm}$, $b=0.958 \mathrm{~nm}, c=0.64 \mathrm{~nm}$, and $\gamma=141.15^{\circ}$, respectively. The obtained values of $a, b$, and $\gamma$ agree well with the lattice spacing determined by the HRTEM image as evident in Fig. 1(a).

The crystalline phases of $\mathrm{Ga}_{2} \mathrm{~S}_{3}$ found in the literatures may be monoclinic, cubic, and hexagonal structures ${ }^{12-14}$. However, their main XRD peak positions are nearly the same with the significant difference only being in the relative intensity change of the diffraction peaks in these phases (e.g. $\mathrm{Ga}_{2} \mathrm{~S}_{3}$ film on the GaAs substrate) ${ }^{13}$. It means that even in the monoclinic phase, $\mathrm{Ga}_{2} \mathrm{~S}_{3}$ can also have a nearly layered type with the hexagonal (defect wurtzite) thin-film form. In fact, the III-VI $\mathrm{Ga}_{2} \mathrm{~S}_{3}$ is a naturally defect semiconductor with one-third of cation sites are vacant (Ga vacancies), similar to that of $\gamma-\mathrm{In}_{2} \mathrm{Se}_{3}{ }^{20}$. The left side of Fig. 1(b) depicts the representative scheme of the atomic arrangement in the metal (Ga)-sheet of the $\mathrm{Ga}_{2} \mathrm{~S}_{3}$ crystal, where $1 / 3$ of the Ga vacancies (" $\square$ ") appeared, and the $\square$ repeats throughout the lattice periodically along $a$ axis. The right side of Fig. 1(b) shows the real tetrahedra of $s p^{3}$ structure of the Ga and $\mathrm{S}$ bonding (i.e. $\mathrm{GaS}_{4}$ tetrahedral molecular) in the $\mathrm{Ga}_{2} \mathrm{~S}_{3}$ crystal above the $\mathrm{Ga}$ metal sheet. The dashed-enclosed line represents the area of the $a$ and $b$ axes as indicated in the left side of Fig. 1(b) by $\vec{a}_{\mathrm{m}}$ and $\vec{b}_{\mathrm{m}}$. This kind of defect structure is easy to form an interfacial disorder of metal atoms in some specific interfaces (IF), which may present in some interfacial lines along the $a$ axis shown in the left side of Fig. 1(b) with a blue arrow on the $c$ plane ${ }^{12}$. The easily-forming IF along the $a$ axis in the defect semiconductor $\mathrm{Ga}_{2} \mathrm{~S}_{3}$ may render an inplane anisotropy of the $c$-plane $\mathrm{Ga}_{2} \mathrm{~S}_{3}$ with the presence of a polarization-dependent optical character along and perpendicular to the crystal's $a$ axis, and we will show and discuss the experimental result later.

To further verify the structural property of the $\mathrm{Ga}_{2} \mathrm{~S}_{3}$ crystals, Raman measurement of the $c$-plane $\mathrm{Ga}_{2} \mathrm{~S}_{3}$ was implemented. Figure SI-2(a) shows the Raman spectrum of the $\mathrm{Ga}_{2} \mathrm{~S}_{3}$ in the energy range of $200-500 \mathrm{~cm}^{-1}$. There are seven peak features at 234, 282, $309,331,348,387$, and $427 \mathrm{~cm}^{-1}$ detected in the $\mathrm{Ga}_{2} \mathrm{~S}_{3}$ crystal. Most of the frequencies can be assigned in terms of internal and external vibrations of tetrahedral $\mathrm{GaS}_{4}$ groups (see SI) ${ }^{21,22}$. The Raman modes sustain the monoclinic crystal symmetry of the as-grown $\mathrm{Ga}_{2} \mathrm{~S}_{3}$ crystals.

Luminescence properties of $\mathrm{Ga}_{2} \mathrm{~S}_{3}$ below band edge. Shown in the left side of Fig. 2(a) is the low-temperature and wide-range PL spectrum of $\mathrm{Ga}_{2} \mathrm{~S}_{3}$ (i.e. $1.25-3.8 \mathrm{eV}$ by a lower-resolution spectrometer with the focal length of $\sim 101 \mathrm{~mm}$ ) on the $c$ plane at $15 \mathrm{~K}$. The excitation source is a $325-\mathrm{nm} \mathrm{He}-\mathrm{Cd}$ laser. Three main bands respectively denoted as D1, D2, and BE emissions are detected. The D1 $(\sim 1.99 \mathrm{eV})$ and D2 $(\sim 2.79 \mathrm{eV})$ bands are the defect related luminescences originated from the donors and acceptors in the $\mathrm{Ga}_{2} \mathrm{~S}_{3}$ crystals while the $\mathrm{BE}$ band $(\sim 3.36 \mathrm{eV})$ must be the bandedge emission. In comparison with the previous results of crystalline and thin-film forms of the $\mathrm{Ga}_{2} \mathrm{~S}_{3}$ in the literatures, it is maybe a near-band-edge emission coming from the $\mathrm{Ga}_{2} \mathrm{~S}_{3}$ crystal ${ }^{13,23}$. The appearance of the band-edge emission BE sustains a better crystalline quality of the as-grown $\mathrm{Ga}_{2} \mathrm{~S}_{3}$ crystal. The PL intensities of the D1 and D2 emissions below band edge are much stronger than that of the band-edge emission $\mathrm{BE}$ observed at $15 \mathrm{~K}$. It is an indication that the monoclinic $\mathrm{Ga}_{2} \mathrm{~S}_{3}$ is a naturally defect semiconductor with the existence of intrinsic defects coming from the imperfection levels consisted in the band gap. Even in such a high-quality crystal (as evident in the HRTEM result of Fig. 1 and the appearance of BE emission in Fig. 2), the defect emissions are still stronger than that of the band edge emission.

To further evaluate the physical origin of the PL emissions of the $\mathrm{Ga}_{2} \mathrm{~S}_{3}$, temperature-dependent PL measurements were carried out. Figure 2(a) also shows a three-dimensional (3D) plot of the relative intensity change and peak-energy shift of the D1, D2, and BE emissions obtained by temperature-dependent PL measurements of $\mathrm{Ga}_{2} \mathrm{~S}_{3}$ in the temperature range between 15 and $300 \mathrm{~K}$. With the temperature increases, the amplitude of the D1 emission was gradually decreased from 15 to $200 \mathrm{~K}$ while the D2 emission revealed similar behavior with $\mathrm{D} 1$ at $\mathrm{T}<180 \mathrm{~K}$. When $\mathrm{T}>180 \mathrm{~K}$, the PL intensities of D1 and D2 are comparable from $\sim 200$ to $\sim 240 \mathrm{~K}$, and then the D2 emission may increase a little bit, and finally the D1 and D2 peaks are merged together to form a broadened peak (centered at $\sim 2.4 \mathrm{eV}$ ) at room temperature. The mechanism of the defect bands inside the $\mathrm{Ga}_{2} \mathrm{~S}_{3}$ defect semiconductor is maybe coming from the 

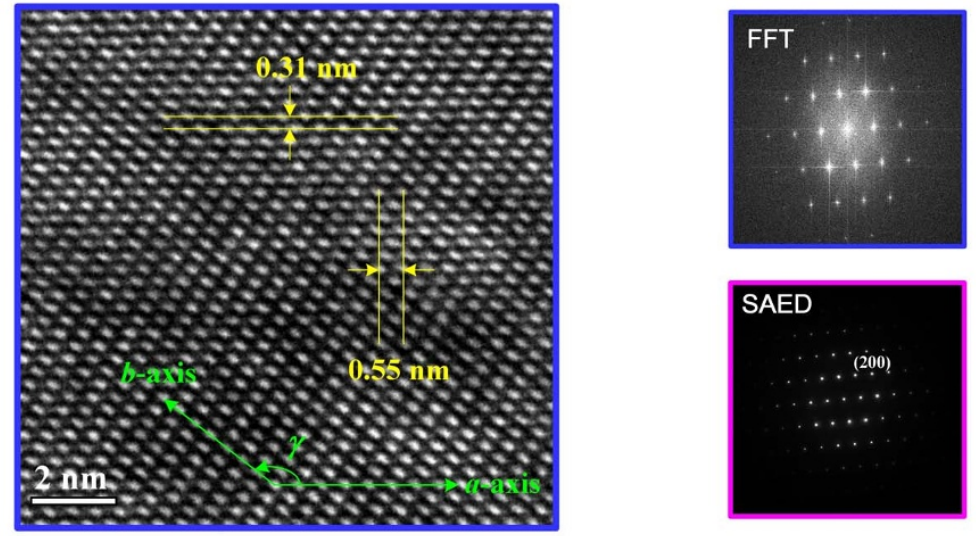

(a)

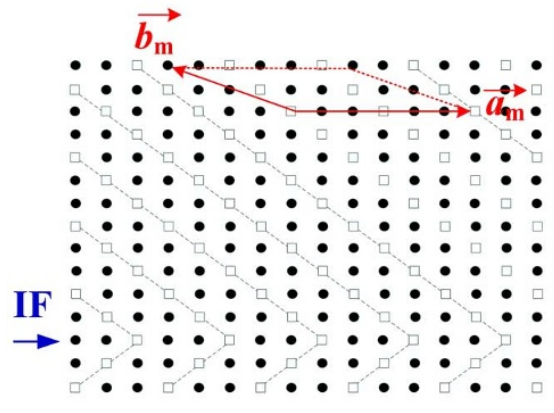

IF: interface $\quad$ Ga $\square$ Vacancy

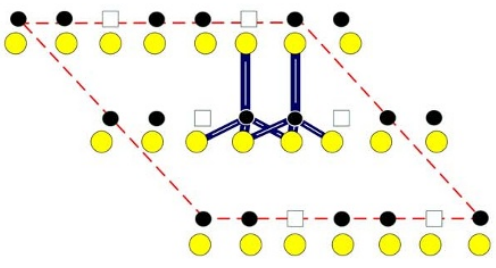

Sulfur

(b)

Figure $1 \mid$ (a) HRTEM images of $\mathrm{Ga}_{2} \mathrm{~S}_{3}$ on the $c$ plane. The orientations of $a$ and $b$ axes are indicated. The overall FFT pattern and the SAED image

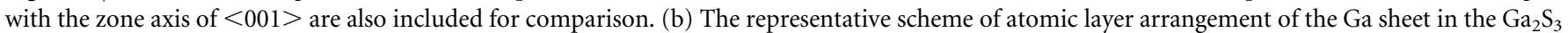
defect semiconductor. The one-third Ga vacancies in the Ga sheet are also depicted. The easily forming interfacial defects (IF) along the $a$ axis on the $c$ plane is indicated (left side). The right side shows the schema of real tetrahedra of $s p^{3}$ structure of the $\mathrm{Ga}$ and $\mathrm{S}$ bonding (i.e. $\mathrm{GaS}_{4}$ tetrahedral molecular) in $\mathrm{Ga}_{2} \mathrm{~S}_{3}$.

formation of sulfur vacancies $\left(\mathrm{V}_{\mathrm{S}}\right)$ by native chalcogen deficiency in the crystal growth as well as the existence of $\mathrm{Ga}$ vacancies $\left(\mathrm{V}_{\mathrm{Ga}}\right)$ inside the imperfection crystal structure. The representative bandedge schemes of monoclinic $\mathrm{Ga}_{2} \mathrm{~S}_{3}$ under room temperature (RT) and at low temperature (LT) are depicted in Fig. 2(b). For the belowband-edge portion, the $\mathrm{V}_{\mathrm{S}}$ states may form a defect donor band $\left(\mathrm{E}_{\mathrm{D}}\right)$ in the $\mathrm{Ga}_{2} \mathrm{~S}_{3}$ while the $\mathrm{V}_{\mathrm{Ga}}$ states may still from some acceptor levels (e.g. $\mathrm{E}_{\mathrm{A} 1}$ and $\mathrm{E}_{\mathrm{A} 2}$ ) existed inside the band gap. The D1 and D2 emissions are, respectively, inferred to come from the lowest $\mathrm{E}_{\mathrm{D}}$ band to the acceptor levels at higher $\mathrm{V}_{\mathrm{Ga}}\left(\mathrm{E}_{\mathrm{A} 2}\right)$ and lower $\mathrm{V}_{\mathrm{Ga}}\left(\mathrm{E}_{\mathrm{A} 1}\right)$ states as shown in Fig. 2(b). At low temperatures (LT), the higher $\mathrm{E}_{\mathrm{A} 2}$ level is nearly empty but the lower $\mathrm{E}_{\mathrm{A} 1}$ level is almost occupied by electrons to render higher D1 but lower D2 intensities. When the temperature increases, thermal ionization effect between the lower $\mathrm{E}_{\mathrm{A} 1}$ and higher $\mathrm{E}_{\mathrm{A} 2}$ acceptor levels causes the $\mathrm{D} 1$ emission decreased but the $\mathrm{D} 2$ enhanced a little bit as shown in the PL result and the indications in Fig. 2(b). For the band-edge emission BE, the PL intensity in Fig. 2(a) is weaker than those of D1 and D2, and the BE is not observable at $\mathrm{T}=300 \mathrm{~K}$. We will evaluate and study the band-edge emission BE by using the temperature-dependent PL measurement in a high-resolution spectrometer with a focal length of $550 \mathrm{~mm}$ later.

Figure 3 shows the temperature-dependent PL spectra (i.e. high resolution) of the $c$-plane $\mathrm{Ga}_{2} \mathrm{~S}_{3}$ in the temperature range between 10 and $150 \mathrm{~K}$ for observation of the optical behavior in the band-edge $\mathrm{BE}$ emission. It is clear and relevant that the $\mathrm{BE}$ emission consists of lower bound-exciton (BX) and higher free-exciton (FX) lumines- cences near the band edge of $\mathrm{Ga}_{2} \mathrm{~S}_{3}$, such as the excitonic transitions of other direct oxide semiconductor as $\mathrm{In}_{2} \mathrm{O}_{3}{ }^{24}$. As shown in Fig. 3, the intensity of the BX feature is higher than that of the FX feature at low temperatures. The energy positions of the excitons are $\mathrm{BX} \approx 3.363 \mathrm{eV}$ and $\mathrm{FX} \approx 3.378 \mathrm{eV}$ at $10 \mathrm{~K}$. When the temperature increases, the intensity of the BX peak decreases rapidly while the FX feature decays slowly. The temperature-energy shift behavior of the FX is shown faster than that of BX and finally they will merge together and dominated by the FX peak at even higher temperatures. This is a general behavior of the bound and free excitons in a direct semiconductor with high luminescent efficiency. The prominent BX feature at low temperatures is probably owing to the peak bound by a neutral donor from the defect donor band $\mathrm{E}_{\mathrm{D}}$ formed by chalcogen deficiency (i.e. $V_{S}$ ). This situation is similar to the donor levels formed by sulfur vacancies to render a donor-bound $\mathrm{D}^{0} \mathrm{X}$ emission in a nanostructure cadmium sulfide material ${ }^{25}$. The FX feature in Fig. 3 is closely related to one of the band-edge excitons existed in the monoclinic $\mathrm{Ga}_{2} \mathrm{~S}_{3}$ and we will evaluate and discuss the direct band-edge structure later.

\section{Discussion}

Optical investigation of the band-edge structure of $\mathrm{Ga}_{2} \mathrm{~S}_{3}$. Figure 4(a) shows the temperature-dependent (unpolarized) TR spectra of $\mathrm{Ga}_{2} \mathrm{~S}_{3}$ on the $c$ plane in the temperature range between 20 and $300 \mathrm{~K}$. At $20 \mathrm{~K}$, there are four band-edge transitions denoted as $\mathrm{E}_{\mathrm{A}}, \mathrm{E}_{\mathrm{B}}, \mathrm{E}_{\mathrm{C} 1}$, and $\mathrm{E}_{\mathrm{C} 2}$ can be detected in the unpolarized $\mathrm{TR}$ spectrum of the $c$-plane $\mathrm{Ga}_{2} \mathrm{~S}_{3}$. The energy values of the band-edge 


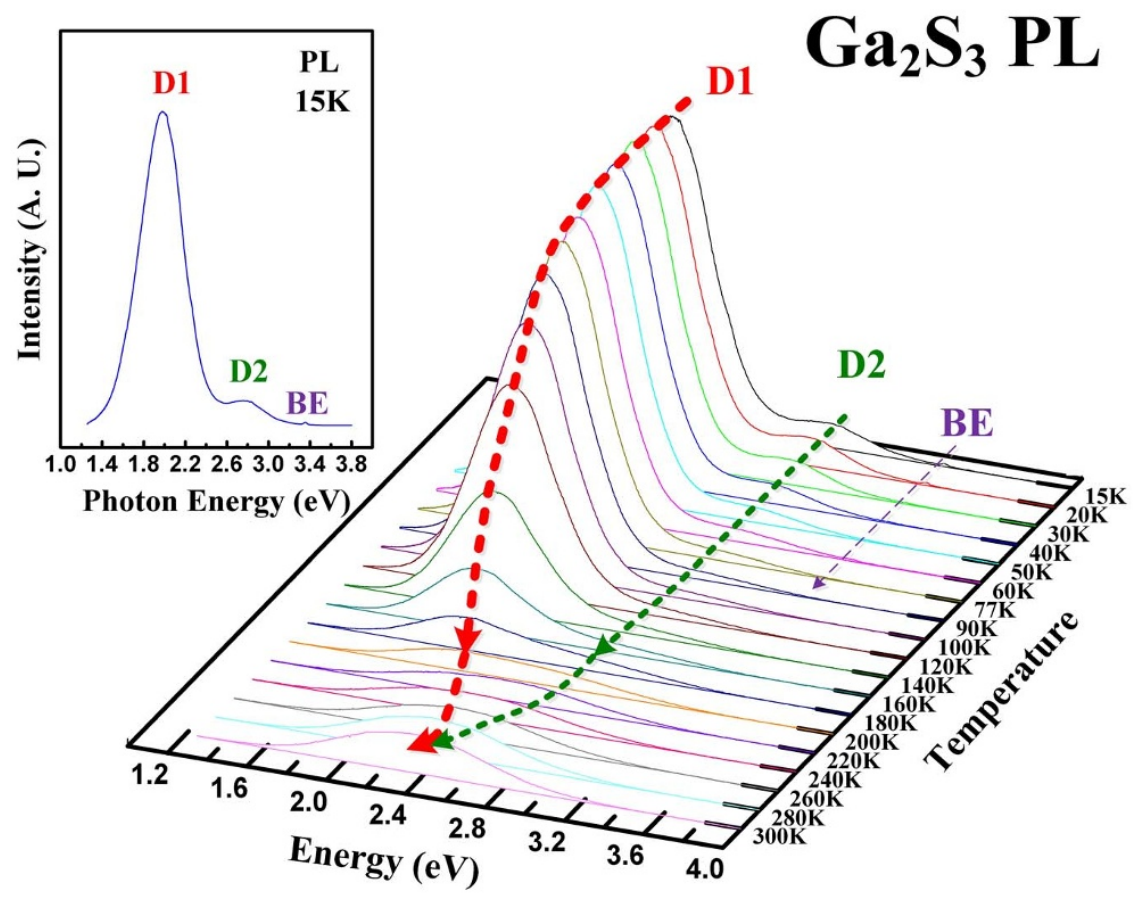

(a)

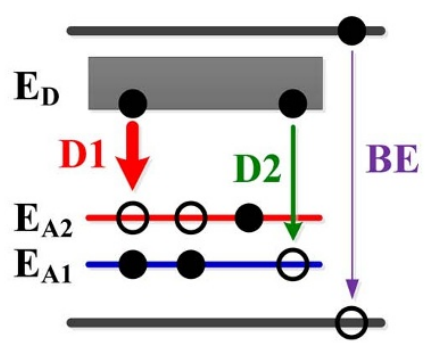

LT

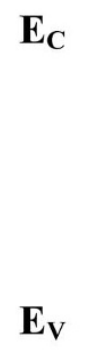

(b)

Figure $2 \mid$ (a) Low-temperature and wide-range PL spectrum of the monoclinic $\mathrm{Ga}_{2} \mathrm{~S}_{3}$ on the $c$ plane at $15 \mathrm{~K}$. The temperature dependent PL spectra of $\mathrm{Ga}_{2} \mathrm{~S}_{3}$ in the temperature range between 15 and $300 \mathrm{~K}$ are also shown. (b) The possible transition mechanism for the defects and band-edge emissions in $\mathrm{Ga}_{2} \mathrm{~S}_{3}$ at low and room temperatures.

transitions at each temperature can be analyzed by using least-square fits of the experimental data to a derivative Lorentzian line-shape functional form expressed $\mathrm{as}^{26}$ :

$$
\mathrm{DR} / \mathrm{R}=\operatorname{Re}\left[\sum_{i} I \cdot e^{j \varphi}\left(\mathrm{E}^{-\mathrm{E}_{i}}+j \Gamma\right)^{-m}\right]
$$

where $i=\mathrm{A}, \mathrm{B}, \mathrm{C} 1$, and $\mathrm{C} 2$, and $I$ and $\varphi$ are the amplitude and phase of the line shape, and $\mathrm{E}_{i}$ and $\Gamma$ are the energy and broadening parameter of the respective interband transition. The value of $m=2$ is used for the first derivative line shape analysis of the band-edge excitons of $\mathrm{Ga}_{2} \mathrm{~S}_{3}$. The obtained values of transition energies from the line-shape fitting of equation (1) are indicated with arrows and their variation traces of temperature-energy shift are shown by dotted lines in Fig. 4(a). The transition energies at $20 \mathrm{~K}$ are $\mathrm{E}_{\mathrm{A}}=3.256 \pm$ $0.010 \mathrm{eV}, \mathrm{E}_{\mathrm{B}}=3.386 \pm 0.008 \mathrm{eV}, \mathrm{E}_{\mathrm{C} 1}=3.440 \pm 0.005 \mathrm{eV}$, and $\mathrm{E}_{\mathrm{C} 2}=3.491 \pm 0.005 \mathrm{eV}$, respectively. With the increase of temperatures, the TR transition features demonstrate an energy red-shift behavior and a line-width broadened character such as the general semiconductor behavior for the $c$-plane $\mathrm{Ga}_{2} \mathrm{~S}_{3}$. The $\mathrm{E}_{\mathrm{A}}$ feature is assigned as the direct band gap of $\mathrm{Ga}_{2} \mathrm{~S}_{3}$, and $\mathrm{E}_{B}$ and $\mathrm{E}_{\mathrm{C}}$ features are correlated with the excitonic transitions near band edge. The origins of the $E_{A}, E_{B}$, and $E_{C}$ transitions are different and the assignments of band-edge transitions of $\mathrm{Ga}_{2} \mathrm{~S}_{3}$ will be verified and identified by the PTR, PL and transmission measurements later. As shown in the low-temperature TR spectra of Fig. 4(a), the most prominent feature of the $c$-plane $\mathrm{Ga}_{2} \mathrm{~S}_{3}$ is the $\mathrm{E}_{\mathrm{C} 1}$ feature $(n=1)$ together with a higher-exciton level $E_{C 2}$ feature $(n=2)$ is also detected. The $\mathrm{E}_{\mathrm{C} 1}$ and $\mathrm{E}_{\mathrm{C} 2}$ transitions may be an excitonic series coming from the $c$-plane $\mathrm{Ga}_{2} \mathrm{~S}_{3}$. The excitonic sequence of the $\mathrm{E}_{\mathrm{C}}$ features of $\mathrm{Ga}_{2} \mathrm{~S}_{3}$ can be further analyzed by using Rydberg series ${ }^{27}$ :

$$
\mathrm{E}_{\mathrm{n}}=\mathrm{E}_{\infty}-\frac{R_{y d}}{\mathrm{n}^{2}} \mathrm{eV}, \mathrm{n}=1,2,3, \ldots,
$$

where $R_{y d}$ is the effective Rydberg constant (binding energy) and $\mathrm{E}_{\infty}$ is the threshold energy of the excitonic sequence $\left(\mathrm{E}_{\mathrm{C}}\right)$. From the obtained values of transition energies of $\mathrm{E}_{\mathrm{Cl}}=3.440$ and $\mathrm{E}_{\mathrm{C} 2}=3.491 \mathrm{eV}$ at $20 \mathrm{~K}$ [see Fig. 1(a)], the effective Rydberg constant is determined to be $R_{y d}=68 \mathrm{meV}$ and threshold energy is 


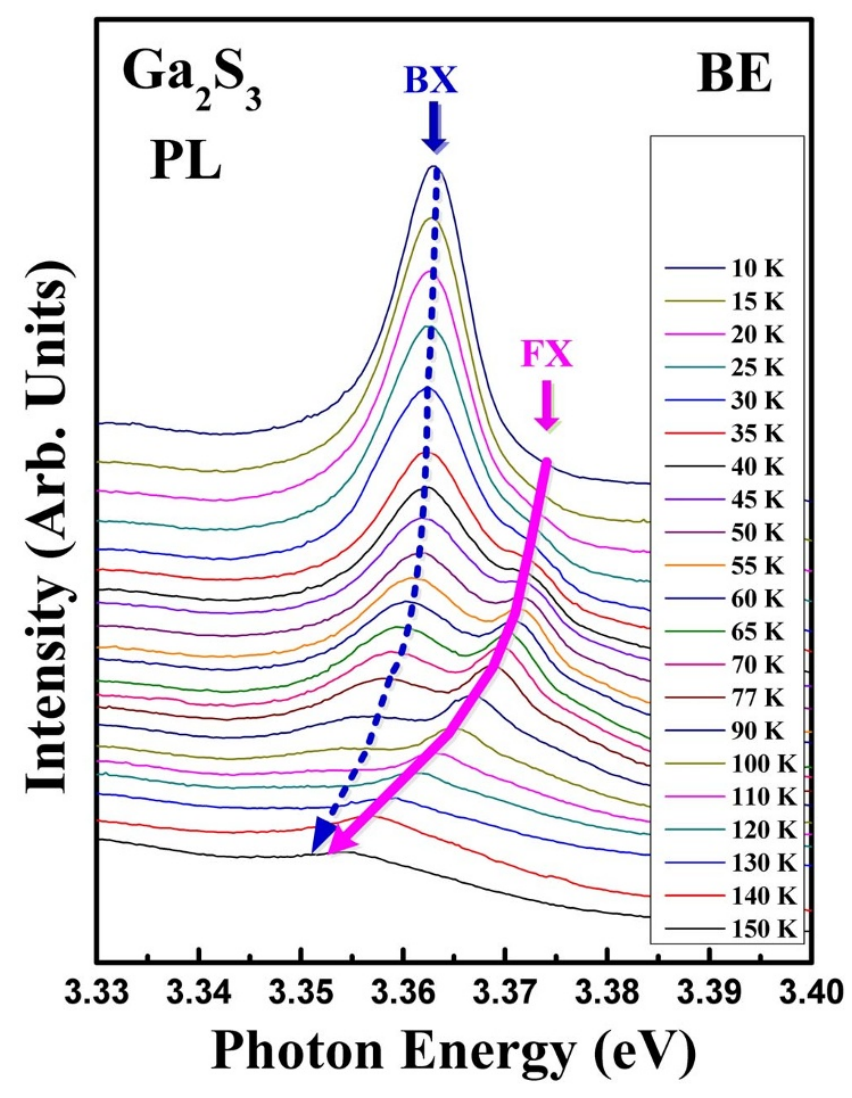

Figure 3 Temperature dependence of high-resolution PL spectra of bound exciton (BX) and free exciton (FX) emissions in the $\mathrm{Ga}_{2} \mathrm{~S}_{3}$ crystal between 10 and $150 \mathrm{~K}$. about $\mathrm{E}_{\infty}=3.508 \mathrm{eV}$ at $20 \mathrm{~K}$. It also means that the binding energy of the $\mathrm{E}_{\mathrm{C} 2}(\mathrm{n}=2)$ feature is about $17 \mathrm{meV}$ (i.e. $\left.\mathrm{E}_{\mathrm{b}}=68 / 2^{2} \mathrm{meV}\right)$. This result can also be verified by the temperature dependence of the TR feature of $\mathrm{E}_{\mathrm{C} 2}$ that was thermally ionized between $180 \mathrm{~K}$ and $220 \mathrm{~K}$ as evident in Fig. 4(a) (i.e. thermal ionization energy is $k \mathrm{~T}=17 \mathrm{meV}$, and the corresponding thermal temperature is about $\mathrm{T}=197 \mathrm{~K}$ ).

Figure 4(b) depicts the temperature dependence of transition energies of $\mathrm{E}_{\mathrm{A}}-\mathrm{E}_{\mathrm{C} 2}$ features obtained by Fig. 4(a) for the $\mathrm{Ga}_{2} \mathrm{~S}_{3}$ crystal by TR. The hollow squares, open circles, hollow triangles, and solid triangles are the energy values of $\mathrm{E}_{\mathrm{A}}, \mathrm{E}_{\mathrm{B}}, \mathrm{E}_{\mathrm{C} 1}$, and $\mathrm{E}_{\mathrm{C} 2}$ features and the solid lines are the least-square fits to a Bose-Einstein type expression responsible for the temperature-energy shift of the $\mathrm{E}_{\mathrm{A}}-\mathrm{E}_{\mathrm{C} 2}$ in $\mathrm{Ga}_{2} \mathrm{~S}_{3}$ expressed as $\mathrm{E}_{\mathrm{i}}(\mathrm{T})=\mathrm{E}_{\mathrm{i} 0}-\mathrm{S}_{\mathrm{i}}<\hbar \Omega_{\mathrm{i}}>\left[\left(\operatorname{coth}<\hbar \Omega_{\mathrm{i}} / k \mathrm{~T}>\right)-1\right]$, where $\mathrm{i}=\mathrm{A}, \mathrm{B}, \mathrm{C} 1$ or $\mathrm{C} 2, \mathrm{E}_{\mathrm{i} 0}$ is the transition energy at $0 \mathrm{~K}, \mathrm{~S}_{\mathrm{i}}$ is a dimensionless coupling constant related to the strength of electron-phonon interaction, and $<\hbar \Omega_{\mathrm{i}}>$ is an average phonon energy. The obtained fitting parameters are $\mathrm{E}_{\mathrm{A} 0}=3.255 \pm 0.005, \mathrm{E}_{\mathrm{B} 0}=3.384 \pm 0.007$, $\mathrm{E}_{\mathrm{C} 10}=3.435 \pm 0.004$, and $\mathrm{E}_{\mathrm{C} 20}=3.491 \pm 0.003 \mathrm{eV}$ for $\mathrm{E}_{\mathrm{i} 0}, \mathrm{~S}_{\mathrm{A}}=15$ $\pm 5, \mathrm{~S}_{\mathrm{B}}=10 \pm 2, \mathrm{~S}_{\mathrm{C} 1}=7 \pm 2$, and $\mathrm{S}_{\mathrm{C} 2}=7 \pm 2$ for $\mathrm{S}_{\mathrm{i}}$, and $<\hbar \Omega_{\mathrm{A}}>=15$ $\pm 6,<\hbar \Omega_{\mathrm{B}}>=13 \pm 5,<\hbar \Omega_{\mathrm{C} 1}>=13 \pm 5$, and $<\hbar \Omega_{\mathrm{C} 2}>=13 \pm$ $5 \mathrm{meV}$ for the $<\hbar \Omega_{\mathrm{i}}>$, respectively, available for the $\mathrm{E}_{\mathrm{A}}, \mathrm{E}_{\mathrm{B}}, \mathrm{E}_{\mathrm{C} 1}$, and $\mathrm{E}_{\mathrm{C} 2}$ transitions. The value of electron (exciton)-phonon interaction constant $\mathrm{S}$ for the $\mathrm{E}_{\mathrm{A}}, \mathrm{E}_{\mathrm{B}}$, and $\mathrm{E}_{\mathrm{C}}$ transitions shows somewhat different in $\mathrm{Ga}_{2} \mathrm{~S}_{3}$. It implies that the variation speeds of temperature-energy shift of the $\mathrm{E}_{\mathrm{A}}, \mathrm{E}_{\mathrm{B}}$, and $\mathrm{E}_{\mathrm{C}}$ transitions are dissimilar. The $\mathrm{E}_{\mathrm{A}}, \mathrm{E}_{\mathrm{B}}$, and $\mathrm{E}_{\mathrm{C}}$ transitions near band edge are maybe coming from different origins in $\mathrm{Ga}_{2} \mathrm{~S}_{3}$.

To further characterize optical anisotropy of the $\mathrm{E}_{\mathrm{A}}-\mathrm{E}_{\mathrm{C}}$ transitions in $\mathrm{Ga}_{2} \mathrm{~S}_{3}$, orientation-dependent and polarization-dependent TR measurements of $\mathrm{Ga}_{2} \mathrm{~S}_{3}$ are respectively carried out. Fig. 5 shows the orientation-dependent TR spectra of (a) $20 \mathrm{~K}$ and (b) $300 \mathrm{~K}$ for the monoclinic $\mathrm{Ga}_{2} \mathrm{~S}_{3}$ near band edge, together with a low-temperature PL spectrum at $20 \mathrm{~K}$ is also included in Fig. 5(a) for com-

\section{$\mathrm{Ga}_{2} \mathrm{~S}_{3}$}
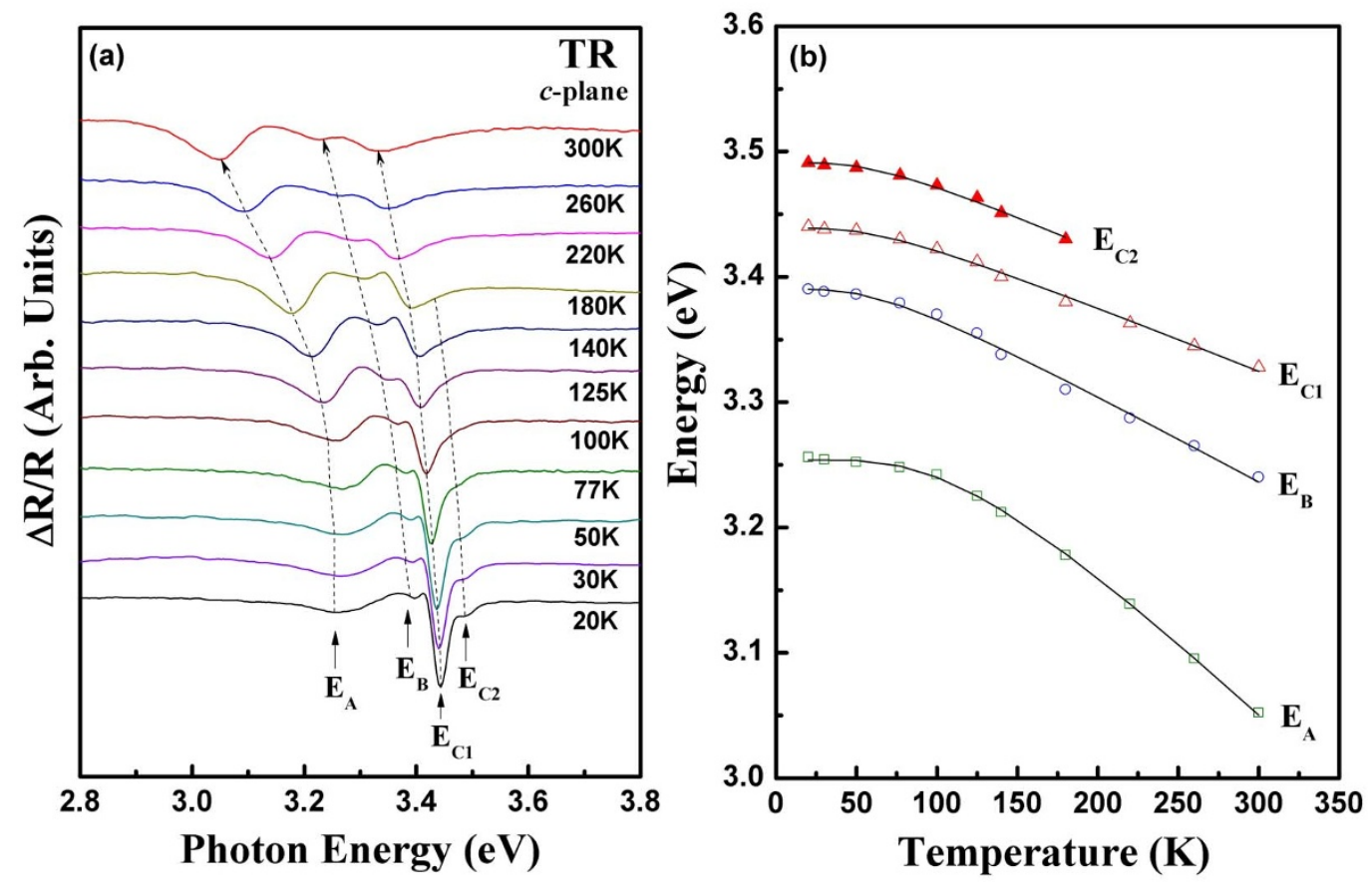

Figure $4 \mid$ (a) Temperature-dependent TR spectra of the $c$-plane $\mathrm{Ga}_{2} \mathrm{~S}_{3}$ near band edge between 20 and $300 \mathrm{~K}$. Four band-edge transitions denoted as $\mathrm{E}_{\mathrm{A}}, \mathrm{E}_{\mathrm{B}}, \mathrm{E}_{\mathrm{C} 1}$, and $\mathrm{E}_{\mathrm{C} 2}$ are observed at low temperatures. (b) Temperature dependence of transition energies of the $\mathrm{E}_{\mathrm{A}}, \mathrm{E}_{\mathrm{B}}, \mathrm{E}_{\mathrm{C} 1}$, and $\mathrm{E}_{\mathrm{C} 2}$ features. The solid lines are the Bose-Einstein type fits to the experimental data from 20 to $300 \mathrm{~K}$. 

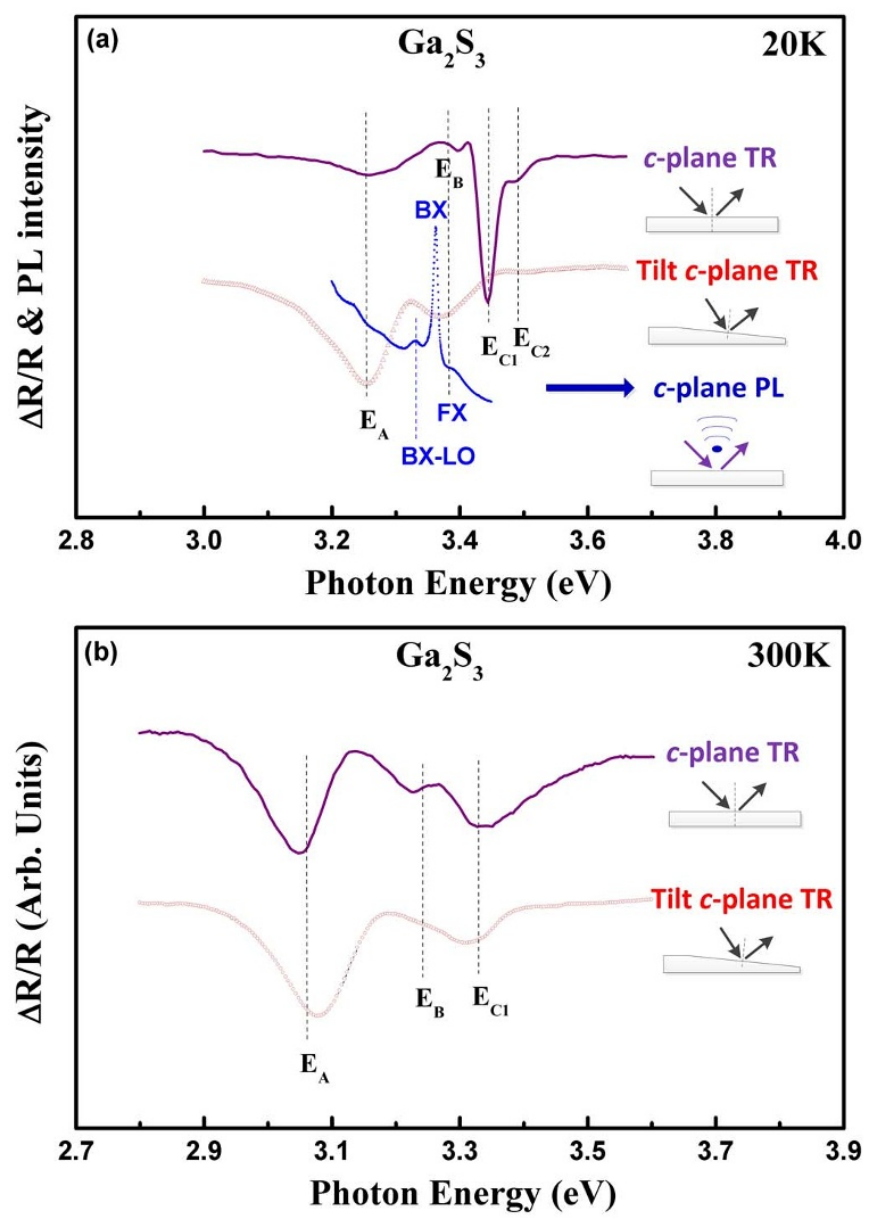

Figure $5 \mid$ Orientation dependent TR measurements on the $c$ plane and tilt $c$ plane (by grinding and polishing sample) for $\mathrm{Ga}_{2} \mathrm{~S}_{3}$ at (a) $20 \mathrm{~K}$ and (b) $300 \mathrm{~K}$. A low-temperature PL spectrum at $20 \mathrm{~K}$ is also included in (a) for comparison.

parison. The orientation-dependent TR measurement was implemented with the probed monochromatic beam impinged on the $c$ plane or on the tilt $c$ plane of $\mathrm{Ga}_{2} \mathrm{~S}_{3}$ as the indications shown in the insets of Fig. 5. The tilt $c$ plane was performed by a tilt polishing of the $\mathrm{Ga}_{2} \mathrm{~S}_{3}$ sample. As shown in Fig. 5(a), for the TR results of $\mathrm{Ga}_{2} \mathrm{~S}_{3}$, we can separate the features into two groups for the $\mathrm{E}_{\mathrm{A}}, \mathrm{E}_{\mathrm{B}}, \mathrm{E}_{\mathrm{C} 1}$, and $\mathrm{E}_{\mathrm{C} 2}$ transitions. One main part consists of the $\mathrm{E}_{\mathrm{A}}$ feature and the other part contains both the $\mathrm{E}_{\mathrm{B}}$ and $\mathrm{E}_{\mathrm{C}}$ transitions. For the $c$-plane $\mathrm{TR}$ result of $\mathrm{Ga}_{2} \mathrm{~S}_{3}$ in Fig. 5(a) (i.e. $20 \mathrm{~K}$, with solid line), the transition amplitudes of $E_{B}$ and $E_{C}$ are larger than that of $E_{A}$, whereas, the tilt $c$ plane TR intensity of the $\mathrm{E}_{\mathrm{A}}$ feature is stronger than those of the other $E_{B}$ and $E_{C}$ features as evident in Fig. 5(a). The anisotropic effect of orientation-dependent TR measurements can also apply to the room-temperature TR spectra as evident in Fig. 5(b). The $\mathrm{E}_{\mathrm{B}}$ and $\mathrm{E}_{\mathrm{C}}$ excitonic transitions are mainly dominant on the $c$ plane and they will decrease their intensities when the $c$ plane is tilted. In fact, the amplitudes of the $\mathrm{E}_{\mathrm{B}}$ and $\mathrm{E}_{\mathrm{C} 1}$ features in the $c$-plane TR spectrum are comparable, whereas the $\mathrm{E}_{\mathrm{B}}$ transition shows much smaller intensity than that of the $\mathrm{E}_{\mathrm{Cl}}$ as displayed in Fig. 5(a). This phenomenon is owing to the partially polarizing effect of the incident light coming from the grating inside the monochromator. The comparable intensity of $\mathrm{E}_{\mathrm{B}}$ and $\mathrm{E}_{\mathrm{C} 1}$ at low temperature will be verified by polarizationdependent TR measurement later. The orientation-dependent TR results in Figs. 5(a) and 5(b) provide conclusive evidence that the transition origin of $\mathrm{E}_{\mathrm{A}}$ is different from those of the other $\mathrm{E}_{\mathrm{B}}$ and $\mathrm{E}_{\mathrm{C}}$ transitions. The $\mathrm{E}_{\mathrm{B}}$ and $\mathrm{E}_{\mathrm{C}}$ are dominated on the $c$ plane while the $\mathrm{E}_{\mathrm{A}}$ is orientation dependent presented for the monoclinic $\mathrm{Ga}_{2} \mathrm{~S}_{3}$. As shown in the $c$-plane PL spectrum in Fig. 5(a), the FX emission nearly agrees well with the $\mathrm{E}_{\mathrm{B}}$ transition and the $\mathrm{E}_{\mathrm{A}}$ feature is maybe too broad to observe in the PL spectrum at $20 \mathrm{~K}$. The BX is the most prominent peak at $\sim 3.362 \mathrm{eV}$ and an additional BX-LO peak (longitudinal-optical-phonon replica) can be detected at $\sim 3.333 \mathrm{eV}$ to render a LO phonon energy approximately to be $29 \mathrm{meV}$. The LO phonon energy matches well with the main Raman vibration branch of $234 \mathrm{~cm}^{-1}$ ( $\mathrm{A}_{1}$ mode $)$ as detected in Fig. SI-2.

In order to distinguish the transition natures of the $\mathrm{E}_{\mathrm{B}}$ and $\mathrm{E}_{\mathrm{C}}$ features, PTR measurements are carried out on the $c$ plane of $\mathrm{Ga}_{2} \mathrm{~S}_{3}$. Fig. 6 shows the PTR spectra near the vicinity of band edge at (a) $300 \mathrm{~K}$ and (b) $50 \mathrm{~K}$, respectively. The measurement configuration of the PTR experiment is presented in Fig. 6(c). A pair of linear polarizers was used, and the PTR experiments were carried out with the linearly polarized light parallel and perpendicular to the $\mathrm{Ga}_{2} \mathrm{~S}_{3}$ crystal's $a$ axis (i.e. $\mathrm{E} \| a$ and $\mathrm{E} \perp a$ ). The $a$ axis is easy to form the planar interfaces (IF) as the indication shown in Fig. 1(b). As shown in Figs. 6(a) and 6(b), the PTR measurements (done on the $c$ plane) of $\mathrm{Ga}_{2} \mathrm{~S}_{3}$ clearly show that $\mathrm{E}_{\mathrm{B}}$ transition is present only in the $\mathrm{E} \| a$ polarization while the $\mathrm{E}_{\mathrm{C}}$ excitons are merely allowed at the $\mathrm{E} \perp a$ polarization. The unpolarized spectrum is approximately a random superposition of the $\mathrm{E} \| a$ and $\mathrm{E} \perp a$ polarized spectra of $\mathrm{Ga}_{2} \mathrm{~S}_{3}$. The intensity of the $\mathrm{E}_{\mathrm{A}}$ feature $(\mathrm{E} \| a$ and $\mathrm{E} \perp a)$ in the PTR spectra at 300 and $50 \mathrm{~K}$ (see Fig. 6) shows similar. The origin of $\mathrm{E}_{\mathrm{A}}$ is different from those of the $\mathrm{E}_{\mathrm{B}}$ and $\mathrm{E}_{\mathrm{C}}$ transitions on the $c$ plane. However, the polarization dependence of the $\mathrm{E}_{\mathrm{B}}$ and $\mathrm{E}_{\mathrm{C}}$ transitions on the $c$ plane of $\mathrm{Ga}_{2} \mathrm{~S}_{3}$ also indicates that $\mathrm{E}_{\mathrm{B}}$ and $\mathrm{E}_{\mathrm{C}}$ are also coming from different origins. The polarization dependency and in-plane anisotropy of the band-edge transitions along some specific crystal axis with line structures (i.e. IF along $a$ axis) have also been found in a triclinic $\mathrm{ReS}_{2}$ layered crystal with the existing $\mathrm{Re}_{4}$ diamond chain clusters along the crystal's $b$ axis $^{27,28}$. The solid lines shown in Figs. 6(a) and 6(b) are the derivative Lorentzian line-shape fits of the PTR spectra using equation (1) and the obtained transition energies are $\mathrm{E}_{\mathrm{A}}=3.052 \mathrm{eV}$, $\mathrm{E}_{\mathrm{B}}=3.240 \mathrm{eV}$, and $\mathrm{E}_{\mathrm{C} 1}=3.328 \mathrm{eV}$ at $300 \mathrm{~K}$, and $\mathrm{E}_{\mathrm{A}}=3.252 \mathrm{eV}$, $\mathrm{E}_{\mathrm{B}}=3.385 \mathrm{eV}, \mathrm{E}_{\mathrm{C} 1}=3.437 \mathrm{eV}$, and $\mathrm{E}_{\mathrm{C} 2}=3.488 \mathrm{eV}$ at $50 \mathrm{~K}$, respectively. The PTR transition amplitudes of $\mathrm{E}_{\mathrm{B}}$ and $\mathrm{E}_{\mathrm{C} 1}$ at $50 \mathrm{~K}$ show comparable in Fig. 6(b). It verifies that the transition probabilities of $\mathrm{E}_{\mathrm{B}}$ and $\mathrm{E}_{\mathrm{C}}$ are comparable in $\mathrm{Ga}_{2} \mathrm{~S}_{3}$, regardless of an observed smaller intensity of $E_{B}$ was detected in the unpolarized TR spectra due to the partially polarizing effect of the monochromator system in Fig. 5(a). The orientation-dependent and polarization-dependent TR measurements confirmed that all the band-edge transitions of $\mathrm{E}_{\mathrm{A}}, \mathrm{E}_{\mathrm{B}}$, and $\mathrm{E}_{\mathrm{C}}$ features are coming from different origins and an asymmetric valence-band top may account for the observed optical-anisotropic effects of the monoclinic $\mathrm{Ga}_{2} \mathrm{~S}_{3}$.

For the monoclinic $\mathrm{Ga}_{2} \mathrm{~S}_{3}$, the highest valence band is consisted of mainly S $3 p$ and some Ga $4 p$ orbitals ${ }^{29}$. Unlike the other $s$ orbital has highly spherical symmetry, the $p$ states in the valence band of $\mathrm{Ga}_{2} \mathrm{~S}_{3}$ are strongly oriented dump-bell shape (axial dependent) distribution, which may enhance the anisotropic character present in the optical property of the diindium trisulfide. The oriented- and polarized-TR spectra may therefore present strongly anisotropic character in the band-edge transitions of the $\mathrm{E}_{\mathrm{A}}, \mathrm{E}_{\mathrm{B}}$, and $\mathrm{E}_{\mathrm{C}}$ features as displayed in the Figs. 5 and 6. For the lowest conduction-band portion of $\mathrm{Ga}_{2} \mathrm{~S}_{3}$, the density of states (DOS) are mainly composed of $\mathrm{Ga} 4 s$ and a little S $3 p$ DOS over 1.7-3.4 eV (see the calculated DOS in Fig. SI-3). For the higher-energy portion (3.4-10 eV), the conduction band is consisted of mainly Ga $4 p$ and partially S $3 p$. For the lowest energy states of the $\mathrm{Ga} 4 s$ doublet, the energy range is about from -8 to $-6 \mathrm{eV}$ below the main valence band. The main valence band is consisted of S $3 p$ and Ga $4 p$ electrons. To further indentify the band gap nature and band-edge transitions of the $\mathrm{Ga}_{2} \mathrm{~S}_{3}$, transmission measurement with the incident light impinged on the $c$ plane of a thin $\mathrm{Ga}_{2} \mathrm{~S}_{3}$ sample was carried out. Figure 7(a) shows the transmittance $(\mathrm{T})$ spectrum of the $\mathrm{Ga}_{2} \mathrm{~S}_{3}$ sample with energy range close to 


\section{$\mathbf{G a}_{2} \mathrm{~S}_{3}$}
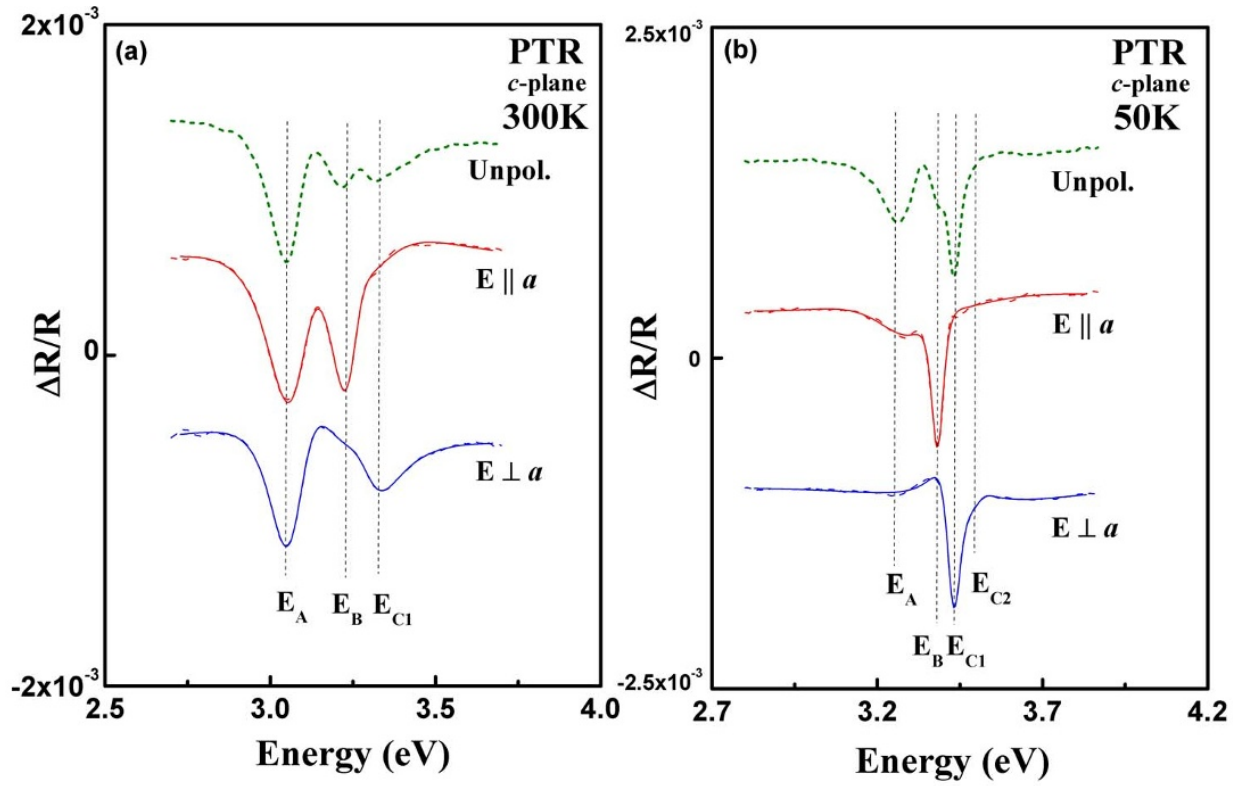

$c$-plane PTR

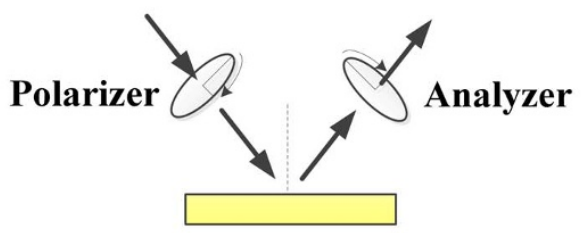

(c)

Figure 6 Polarization-dependent TR spectra of (a) $300 \mathrm{~K}$ and (b) $50 \mathrm{~K}$ for the c-plane $\mathrm{Ga}_{2} \mathrm{~S}_{3}$ near band edge. The measurements are done with the linearly polarized light parallel and perpendicular to the crystal's $a$ axis. (c) The representative scheme for the $c$-plane PTR measurement of Ga $\mathrm{S}_{3}$.

the band-edge portion. For comparison purpose the derivative $\mathrm{T}$ spectrum (Derv. T) is calculated, together with the TR spectrum of the $c$-plane $\mathrm{Ga}_{2} \mathrm{~S}_{3}$ is also included in Fig. 7(a) for contrast. The absorption edge in the T spectrum of Fig. 7(a) shows two stair steps positioned in between 2.8 and $3.4 \mathrm{eV}$ at $300 \mathrm{~K}$. It is very interesting that the $\mathrm{E}_{\mathrm{A}}$ and $\mathrm{E}_{\mathrm{B}}$ transitions in TR are matching well with the Derv.
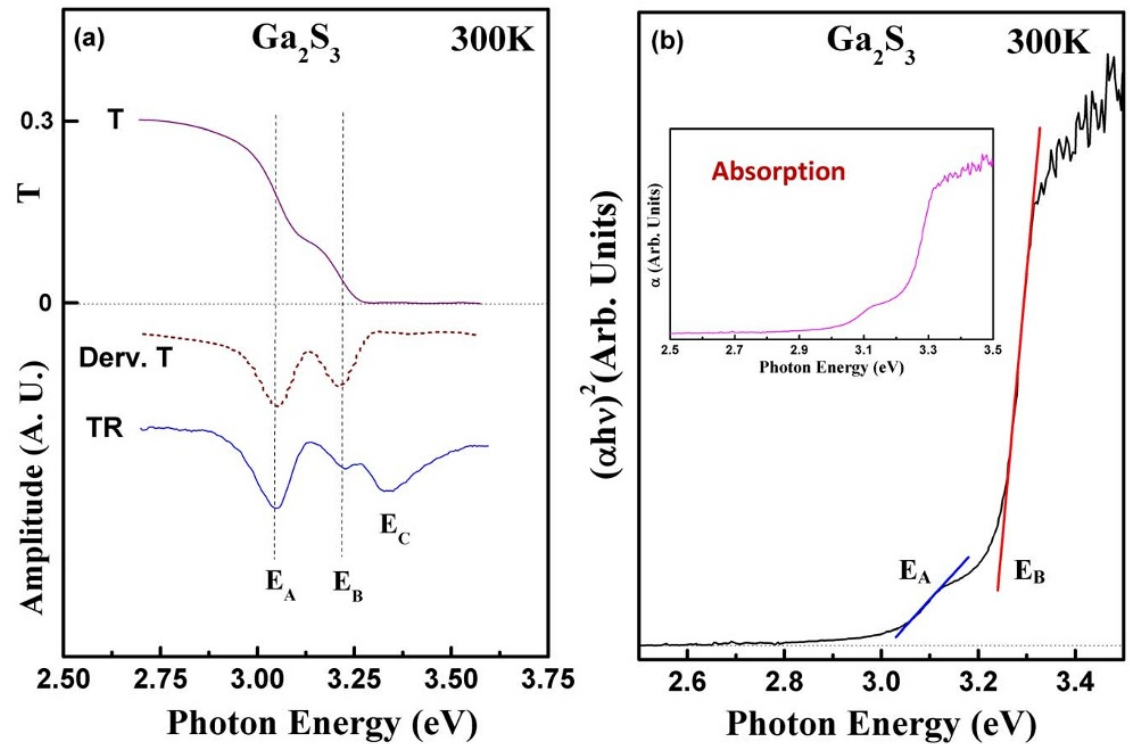

Figure $7 \mid$ (a) Transmittance, derivative transmittance, and TR spectra of $\mathrm{Ga}_{2} \mathrm{~S}_{3}$ near band edge. (b) The absorption spectrum and the result of $(\alpha \mathrm{hv})^{2}$ vs. $\mathrm{h} v$ for determining the transition energies of $\mathrm{E}_{\mathrm{A}}$ and $\mathrm{E}_{\mathrm{B}}$. 


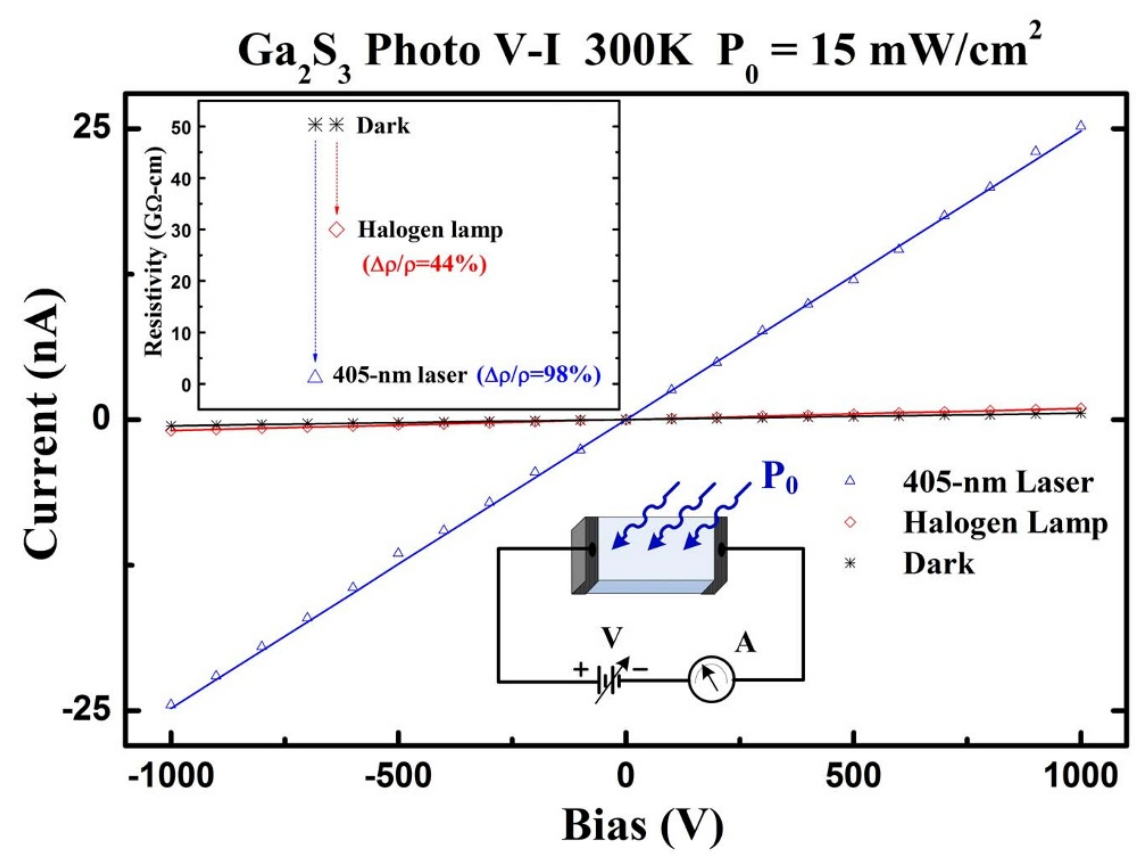

Figure 8 The experimental results of Photo V-I measurement under different illumination conditions of dark, halogen lamp and 405-nm laser for a $\mathrm{Ga}_{2} \mathrm{~S}_{3}$ photoconductor. The photo-resistivities and measurement setup are, respectively, depicted in the upper and lower insets.

T spectrum calculated from $T$ (i.e. TR is also derivative line shape). It suggests that $\mathrm{E}_{\mathrm{A}}$ and $\mathrm{E}_{\mathrm{B}}$ are two of the direct band-edge transitions in $\mathrm{Ga}_{2} \mathrm{~S}_{3}$. The calculated absorption coefficient $\alpha$ in the inset of Fig. 7(b) also sustains that the spectral analysis of both $\mathrm{E}_{\mathrm{A}}$ and $\mathrm{E}_{\mathrm{B}}$ followed $\alpha$ $\propto\left(\mathrm{E}-\mathrm{E}_{\mathrm{i}}\right)^{1 / 2}$, a direct allowed transition $(\mathrm{i}=\mathrm{A}$ or $\mathrm{B})$. The converted spectrum of $(\alpha h v)^{2}$ versus hv plot shown in Fig. $7(\mathrm{~b})$ also reveals that the linear fitting results get the energy values of $\mathrm{E}_{\mathrm{A}}=3.05 \mathrm{eV}$ and $\mathrm{E}_{\mathrm{B}}=3.24 \mathrm{eV}$ for the monoclinic $\mathrm{Ga}_{2} \mathrm{~S}_{3}$, respectively. The energy values of $E_{A}$ and $E_{B}$ match quite well with those obtained by TR and PTR measurements as evident in the Figs. 5-7 at room temperature. The TR technique is a powerful tool for probing direct band gap and direct inter-band transitions of semiconductors ${ }^{24,30}$. The energy positions of the band-edge transitions in TR show good agreement with the absorption edge of the transmittance spectrum of $\mathrm{Ga}_{2} \mathrm{~S}_{3}$. This result sustains that $\mathrm{Ga}_{2} \mathrm{~S}_{3}$ is a direct semiconductor with a direct band gap positioned at $\mathrm{E}_{\mathrm{A}} \approx 3.052 \mathrm{eV}$ at room temperature. With this energy value, the $\mathrm{Ga}_{2} \mathrm{~S}_{3}$ may be a potential material available for fabrication of white lighting device and a UV photoelectric conversion cell.

To evaluate the UV photoconduction behavior of the $\mathrm{Ga}_{2} \mathrm{~S}_{3}$ crystal, Photo V-I measurements are implemented at $300 \mathrm{~K}$. Figure 8 shows the Photo V-I measurement results of the $\mathrm{Ga}_{2} \mathrm{~S}_{3}$ crystal under different illumination conditions of dark, halogen lamp, and 405-nm laser. The measurement setup is depicted in the lower inset of Fig. 8. The illumination power density for the halogen lamp and the 405$\mathrm{nm}$ solid state laser was kept at $\mathrm{P} \approx 15 \mathrm{~mW} \cdot \mathrm{cm}^{-2}$. The scanning voltage range is from -1000 to $1000 \mathrm{~V}$. Nearly a linear relationship for the Photo V-I curves was obtained (i.e. by a linear fitting). The obtained values of resistivity are $\rho=53.4 \mathrm{G} \Omega$-cm for the dark condition, $\rho=30 \mathrm{G} \Omega-\mathrm{cm}$ for the halogen lamp, and $\rho=1.15 \mathrm{G} \Omega-\mathrm{cm}$ for the 405-nm laser illumination, respectively. The resistivities under dark, halogen lamp, and 405-nm laser illumination are respectively depicted as star, hollow diamond, and open triangle in the upper inset of Fig. 8. The halogen lamp represents a broadband blackbody radiation with a main hump peak close to approximate $1.9 \mathrm{eV}$, which also demonstrates a decreased and lowered intensity toward to the UV range. The photoconduction ratio of halogen lamp in Fig. 8 is about $\Delta \rho / \rho=44 \%$. However, for the $405-\mathrm{nm}$ laser (with the same power density) illumination, the photoconduction ratio can reach $\Delta \rho / \rho=98 \%$. The photon energy of the $405-\mathrm{nm}$ laser is $3.062 \mathrm{eV}$, which is larger than that of the direct gap (i.e. $\mathrm{E}_{\mathrm{A}}=3.052 \mathrm{eV}$ ) in the $\mathrm{Ga}_{2} \mathrm{~S}_{3}$ to render a significant photoresponse in the violet to UV region in Fig. 8.

In summary, the band-edge structure, defect luminescence, and excitonic transition of $\mathrm{Ga}_{2} \mathrm{~S}_{3}$ crystals have been detailed characterized by PL, optical absorption, orientation-dependent and polarization-dependent TR measurements. The $\mathrm{Ga}_{2} \mathrm{~S}_{3}$ crystals have been grown by CVT method using $\mathrm{ICl}_{3}$ as the transport agent. HRTEM, XRD and Raman measurements confirmed high quality and monoclinic phase of the as-grown $\mathrm{Ga}_{2} \mathrm{~S}_{3}$ crystals. The interfacial defects IF are easy to form on the $c$ plane along $a$ axis, which results in optical anisotropy of $\mathrm{Ga}_{2} \mathrm{~S}_{3}$ with polarizations along $a$ and perpendicular to $a$ axis. $\mathrm{Ga}_{2} \mathrm{~S}_{3}$ is a naturally defect semiconductor and the defects caused by $\mathrm{V}_{\mathrm{Ga}}$ and $\mathrm{V}_{\mathrm{S}}$ vacancies render a visible luminescence ranging from 1.5 to $3 \mathrm{eV}$, which is detected by the PL spectra from low to room temperatures. Especially, the free exciton and bound exciton emissions are firstly observed in the $\mathrm{Ga}_{2} \mathrm{~S}_{3}$ crystal. There are three main band-edge transitions $\mathrm{E}_{\mathrm{A}}, \mathrm{E}_{\mathrm{B}}$, and $\mathrm{E}_{\mathrm{C}}$ can be detected in the TR spectra of $\mathrm{Ga}_{2} \mathrm{~S}_{3}$. The $\mathrm{E}_{\mathrm{A}}$ transition is the direct band gap of $\mathrm{Ga}_{2} \mathrm{~S}_{3}$ (i.e. $\mathrm{E}_{\mathrm{A}}=3.052 \mathrm{eV}$ ). The $\mathrm{E}_{\mathrm{B}}$ and $\mathrm{E}_{\mathrm{C}}$ transitions are dominated on the $c$ plane and will reveal intensity degradation if the TR measurements are carried out on a tilt $c$ plane by tilt polishing the $\mathrm{Ga}_{2} \mathrm{~S}_{3}$ sample. The in-plane anisotropy of the $c$-plane $\mathrm{Ga}_{2} \mathrm{~S}_{3}$ clear shows that the $\mathrm{E}_{\mathrm{B}}$ transition merely allows along the $\mathrm{E} \| a$ polarization while the $\mathrm{E}_{\mathrm{C}}$ transition is only present in the $\mathrm{E} \perp a$ polarized spectra. The energy position of $\mathrm{E}_{\mathrm{B}}$ is matching well with the $\mathrm{FX}$ emission of $\mathrm{Ga}_{2} \mathrm{~S}_{3}$ at low temperature. The $\mathrm{E}_{\mathrm{C}}$ is an excitonic series (observed by $\mathrm{E}_{\mathrm{C} 1}$ and $\mathrm{E}_{\mathrm{C} 2}$ levels at low temperatures) whose binding energy is determined to be $R_{y d}=68 \mathrm{meV}$. The highly-oriented S $3 p$ and Ga $4 p$ states consisted in the valence-band top renders the strong optical anisotropic behavior of the band-edge transitions in the $\mathrm{Ga}_{2} \mathrm{~S}_{3} . \mathrm{Ga}_{2} \mathrm{~S}_{3}$ is a wide band gap semiconductor and the Photo V-I measurements under dark, halogen lamp, and 405-nm laser illumination conditions confirmed blue to UV photoelectric conversion behavior of the $\mathrm{Ga}_{2} \mathrm{~S}_{3}$ crystal. The sulfide compound is not only a white-light emitting material but also a UV optical absorber. 


\section{Methods}

Crystal growth. The $\mathrm{Ga}_{2} \mathrm{~S}_{3}$ crystals were grown by chemical vapor transport using $\mathrm{ICl}_{3}$ as a transport agent ${ }^{31}$. The growth was conducted in a horizontal three-zone tube furnace with a temperature gradient setting as $850{ }^{\circ} \mathrm{C} \leftarrow 920{ }^{\circ} \mathrm{C} \rightarrow 850{ }^{\circ} \mathrm{C}$ for simultaneously growing two sealed quartz ampoules. Prior to the crystal growth, the pure elements of $\mathrm{Ga}$ and $\mathrm{S}$ with proper stoichiometry combined with a small amount of transport agent $\left(\mathrm{ICl}_{3}\right)$ were put into the quartz ampoule, which was then cooled using liquid nitrogen, evacuated to approximately $10^{-6} \mathrm{Torr}$, and then sealed. The reaction was maintained for $200 \mathrm{~h}$ for growing large single crystals. After the growth was completed, the as-grown crystals exhibited white and light-yellow colored.

Optical measurements. The TR experiments were implemented using indirect heating manner with a gold-evaporated quartz plate as the heating element. The thin sample of $\mathrm{Ga}_{2} \mathrm{~S}_{3}$ was closely attached on the heating element by silicone grease ${ }^{30}$. The on-off heating disturbance uniformly modulates the layered sample periodically. An $150 \mathrm{~W}$ xenon-arc lamp filtered by a PTI $0.2-\mathrm{m}$ monochromator provided the monochromatic light. The incident light was focused onto the sample with a spot size less than thousand $\mu \mathrm{m}^{2}$. The reflected light from the sample surface was collected and detected by a Hamamatsu H3177-51 PMT module. The signal was detected and recorded via an EG\&G model 7265 lock-in amplifier and a personal computer. A closed-cycle cryogenic refrigerator with a thermometer controller facilitated the temperature-dependent measurements. For PTR measurement, one pair of GlanTaylor-prism polarizer ( $320 \mathrm{~nm}-2200 \mathrm{~nm}$ ) was employed. High-resolution PL measurements were carried out in a spectral measurement system where an iHR 550 imaging spectrometer equipped with a 2400 groves $/ \mathrm{mm}$ grating acted as the optical dispersion unit. The low-resolution PL spectra were detected by a QE65000 spectrometer. The pumping light source is a helium-cadmium laser $(\lambda=325 \mathrm{~nm})$. Photo V-I experiments were performed using two dissimilar light sources of tungsten halogen lamp and $405-\mathrm{nm}$ laser as the solar emulators. The averaged power density was adjusted and maintained at approximate $15 \mathrm{~mW} / \mathrm{cm}^{2}$ by using the monitor of an OPHIR optical power meter equipped with a broadband high-sensitivity thermal sensor $(0.15-6 \mu \mathrm{m})$. To prepare the sample for Photo V-I measurements, the specimen of $\mathrm{Ga}_{2} \mathrm{~S}_{3}$ was cut into a rectangular shape with dimension of $3.15 \times 2.95 \times$ $0.3 \mathrm{~mm}^{3}$. The two ends of each specimen were then coated with Au/In, which served as the ohmic-contact electrodes by sputtering. To perform the optical measurements, the ohmic-contact electrodes on each sample were shielded with light. The Photo V-I measurements were implemented using the auxiliary of a semiconductor parameter analyzer. The voltage scanning range was set at -1000 to $1000 \mathrm{~V}$.

1. Mafi, E., Soudi, A. \& Gu, Y. Electronically driven amorphization in phase-change $\mathrm{In}_{2} \mathrm{Se}_{3}$ nanowires. J. Phys. Chem. C 116, 22539-22544 (2012).

2. Li, Y. et al. Thermal phase transformation of $\mathrm{In}_{2} \mathrm{Se}_{3}$ nanowires studied by in situ synchrotron radiation X-ray diffraction. J. Mater. Chem. 21, 6944-6947 (2011).

3. Jones, C. Y. \& Edwards, J. G. Observation of a phase transformation of $\mathrm{Ga}_{2} \mathrm{~S}_{3}$ in a quartz effusion cell above $1230 \mathrm{~K}$ by means of neutron scattering. J. Phys. Chem. B 105, 2718-2724 (2001).

4. Ho, C. H. \& Lin, S. L. Optical properties of interband transitions of layered gallium sulfide. J. Appl. Phys. 100, 083508-1 to 083508-6 (2006).

5. Goodyear, J. \& Steigmann, G. A. The crystal structure of $\alpha-\mathrm{Ga}_{2} \mathrm{~S}_{3}$. Acta Cryst. 16, 946-949 (1963)

6. Ho, C. H., Wu, C. C. \& Cheng, Z. H. Crystal structure and electronic structure of $\mathrm{GaS}_{1-\mathrm{x}} \mathrm{Se}_{\mathrm{x}}$ series layered solids. J. Cryst. Growth 279, 321-328 (2005).

7. Peressi, M. \& Baldereschi, A. Structure and electronic properties of $\mathrm{Ga}_{2} \mathrm{Se}_{3}$. J. Appl. Phys. 83, 3092-3095 (1998)

8. Ho, C. H. \& Huang, K. W. Visible luminescence and structural property of $\mathrm{GaSe}_{1-\mathrm{x}} \mathrm{S}_{\mathrm{x}}(0 \leq \mathrm{x} \leq 1)$ series layered crystals. Solid State Commun. 136, 591-596 (2005)

9. Peršn, M., Čelustka, B., Popović, S. \& Peršn, A. Some electrical and optical characteristics of thin films of $\mathrm{Ga}_{2} \mathrm{Se}_{3}$. Thin Solid Films 37, L61-L62 (1976).

10. Yoon, C. S. et al. Optical properties of $\mathrm{Ga}_{2} \mathrm{Se}_{3}$ and $\mathrm{Ga}_{2} \mathrm{Se}_{3}: \mathrm{Co}^{2+}$ single. crystals. J. Phys. Chem. Solids 62, 1131-1137 (2001).

11. Collin, G. et al. Preparation and structure of $\alpha-\mathrm{Ga}_{2} \mathrm{~S}_{3}$. Mat. Res. Bull. 11, 285-292 (1976).

12. Tomas, A., Guymont, M., Pardo, M. P., Guittard, M. \& Flahaut, J. X-ray diffraction and electron microscopy studies of $\alpha$ - and $\beta-\mathrm{Ga}_{2} \mathrm{~S}_{3}$. Phys. Stat. Sol. (a) 107, 775-784 (1988).

13. Liu, H. F. et al. Synthesis and phase evolutions in layered structure of $\mathrm{Ga}_{2} \mathrm{~S}_{3}$ semiconductor thin films on epiready GaAs (111) substrate. ACS Appl. Mater. Interfaces 6, 3501-3507 (2014).

14. Barbouth, N., Berthier, Y., Oudar, J., Moison, J.-M. \& Bensoussan, M. The first steps of the sulfurization of III-V compounds. J. Electrochem. Soc.: Solid-State Sci. Technol., 1663-1666 (1986).
15. Ren, J. et al. Broadband near-infrared emission of chromium-doped sulfide glassceramics containing $\mathrm{Ga}_{2} \mathrm{~S}_{3}$ nanocrystals. Opt. Lett. 37, 5043-5045 (2012).

16. Yoon, C. S. et al. Blue photoluminescence of $\alpha-\mathrm{Ga}_{2} \mathrm{~S}_{3}$ and $\alpha-\mathrm{Ga}_{2} \mathrm{~S}_{3}: \mathrm{Fe}^{2+}$ single crystals. Appl. Phys. Lett. 83, 1947-1949 (2003).

17. Chen, F., Dai, S., Lin, C., Yu, Q. \& Zhang, Q. Performance improvement of transparent germanium-gallium-sulfur glass ceramic by gold doping for thirdorder optical nonlinearities. Opt. Express 21, 24847-24855 (2013).

18. Shakikh, H. A. E., Abdal-Rahman, M., Belal, A. E. \& Ashraf, I. M. Photoconductivity studies of gallium sesquisulphide single crystals. J. Phys. D: Appl. Phys. 29, 466-469 (1996).

19. Kim, W. T., Kim, H. S., Kim, Y. G. \& Hahn, S. R. Optical energy gaps of $\operatorname{In}_{2-\mathrm{x}} \mathrm{Ga}_{\mathrm{x}} \mathrm{S}_{3}$ thin films prepared by spray pyrolysis. J. Mater. Sci. Lett. 6, 479-480 (1987).

20. Ho, C. H. \& Chen, Y. C. Thickness-tunable band gap modulation in $\gamma-\mathrm{In}_{2} \mathrm{Se}_{3} . R S C$ Adv. 3, 24896-24899 (2013)

21. Lucazeau, G. \& Leory, J. Etude vibrationnelle de $\alpha \mathrm{Ga}_{2} \mathrm{~S}_{3}$. Spectrochimica Acta 34A, 29-32 (1978).

22. Julien, C. et al. Vibrational studies of copper thiogallate solid solutions. Mater. Sci. Eng. B57, 102-109 (1999).

23. Lee, J. S., Won, Y. H., Kim, H. N., Kim, C. D. \& Kim, W. T. Photoluminescence of $\mathrm{Ga}_{2} \mathrm{~S}_{3}$ and $\mathrm{Ga}_{2} \mathrm{~S}_{3}: \mathrm{Mn}$ single crystals. Solid State Commun. 97, 1101-1104 (1996).

24. Ho, C. H., Chan, C. H., Tien, L. C. \& Huang, Y. S. Direct optical observation of band-edge excitons, band gap, and Fermi level in degenerate semiconducting oxide nanowires $\mathrm{In}_{2} \mathrm{O}_{3}$. J. Phys. Chem. C 115, 25088-25096 (2011).

25. Liu, B. et al. Exciton-Related Photoluminescene and Lasing in CdS Nanobelts. J. Phys. Chem. C 115, 12826-12830 (2011).

26. Aspnes, D. E. Modulation Spectroscopy/Electric Field Effects on the Dielectric Fuction of Semiconductors, edited by Balkanski, M. Handbook on Semiconductors 2, Chap. 4A, 109-154 (North Holland: Amsterdam, 1980).

27. Ho, C. H., Yen, P. C., Huang, Y. S. \& Tiong, K. K. Photoreflectance study of the excitonic transitions of rhenium disulphide layer compounds. Phys. Rev. B 66, 245207-1 to $245207-5$ (2002)

28. Tongay, S. et al. Monolayer behavior in bulk $\mathrm{ReS}_{2}$ due to electronic and vibrational decoupling. Nat. Commun. 5, 4252 (2014)

29. Zhang, M. J., Jiang, X. M., Zhou, L. J. \& Guo, G. C. Two phases of $\mathrm{Ga}_{2} \mathrm{~S}_{3}$ : promising infrared second-order nonlinear optical materials with very high laser induced damage thresholds. J. Mater. Chem. C 1, 4754-4760 (2013).

30. Ho, C. H., Lee, H. W. \& Cheng, Z. H. Practical thermoreflectance design for optical characterization of layer semiconductors. Rev. Sci. Instrum. 75, 1098-1102 (2004).

31. Ho, C. H. Growth and characterization of near-band-edge transitions in $\beta-\mathrm{In}_{2} \mathrm{~S}_{3}$ single crystals. J. Cryst. Growth 312, 2718-2723 (2010).

\section{Acknowledgments}

The authors would like to acknowledge the funding support from the Ministry of Science and Technology of Taiwan under the grant No. 101-2221-E-011-052-MY3.

\section{Author contributions}

C.H.H. conceived the idea and conducted the experiments. C.H.H. also grew the crystals, analyzed (calculated) the data, and wrote the manuscript. H.H.C. performed the optical measurement and structural characterization.

\section{Additional information}

Supplementary information accompanies this paper at http://www.nature.com/ scientificreports

Competing financial interests: The authors declare no competing financial interests. How to cite this article: Ho, C.-H. \& Chen, H.-H. Optically decomposed near-band-edge structure and excitonic transitions in $\mathrm{Ga}_{2} \mathrm{~S}_{3}$. Sci. Rep. 4, 6143; DOI:10.1038/srep06143 (2014).

This work is licensed under a Creative Commons Attribution-NonCommercialNoDerivs 4.0 International License. The images or other third party material in this article are included in the article's Creative Commons license, unless indicated otherwise in the credit line; if the material is not included under the Creative Commons license, users will need to obtain permission from the license holder in order to reproduce the material. To view a copy of this license, visit http:// creativecommons.org/licenses/by-nc-nd/4.0/ 